\title{
Estratégia de leitura na Educação Inclusiva: ler buscando significados $^{1}$
}

Fernanda de Paula Coelho ${ }^{2}$

Resumo: A educação inclusiva visa atender os alunos com necessidades especiais ou não de igual maneira; uns não podem se sentir menos privilegiados que os outros, sendo assim, conteúdos e atividades precisam ser adaptados para atender a todos, independente da disciplina. Com o ensino de Botânica os alunos conhecem no ambiente e em sala de aula formas diferenciadas de folhas e suas estruturas, percebendo que há uma variedade de formas de folhas, flores com as suas belezas e cheiros. Os trabalhos desenvolvidos com os alunos são diferenciados, pois vão de sujar as mãos até o pé, fazendo assim com que se sintam mais motivados e empolgados com o novo. É uma forma diferente de ensinar e divertida de aprender que estimula o aluno na busca pelo conhecimento. Mostrando como é possível através do lúdico e do método multisensorial despertar o interesse e facilitar o processo de ensino-aprendizagem de crianças portadoras ou não de necessidades especiais.

Palavras-Chave: Inclusão; Botânica; Atividades

Abstract: Inclusive education seeks to serve students with special needs or not in the same way; some may not feel less privileged than others and thus content and activities need to be adapted to cater for everyone, regardless of discipline. With the teaching of Botany students learn in the environment and in the classroom differentiated leaf shapes and structures realizing that there are a variety of leaf shapes, flowers with their beauty and smells. Studies carried out with students are differentiated, as they will getting their hands dirty to the foot, thus making them feel more motivated and excited about the new. It's a different way to teach and fun to learn that stimulates the student in the pursuit of knowledge forms. Showing how it is possible through the

1 Artigo de conclusão de curso apresentado ao Programa de Pós-graduação em Educação Inclusiva, Especial e Políticas de Inclusão, sob orientação da Profa. Beatriz Pazini Ferreira (Faculdade Eficaz de Maringá/PR).

${ }^{2}$ Pós-graduação em Educação Inclusiva, Especial e Políticas de Inclusão (Faculdade Eficaz de Maringá/ PR). Contato: fernanicoelho@gmail.com 
playful and the multisensory method to arouse interest and facilitate the teaching and learning of carriers or not of special needs children.

Keywords: Inclusion; Botany; Activities

Este trabalho tem por objetivo tirar os alunos do ensino fundamental do modelo de ensino tradicional. Um dos conteúdos que pode contribuir nesse sentido é o ensino de Botânica. Atividades diferenciadas dentro e fora da sala de aula para o reconhecimento da diversidade das plantas e suas estruturas, ao invés de tabelas e nomes decorados com "macetes".

Desta forma se proporá a realização de atividade com folhas vivas e saídas de campo, para que alunos conheçam com a leitura dos sentidos suas formas, funções e belezas.

Alunos com necessidades especiais precisam de estímulos e atenção para realizar trabalhos; com as saídas de campo vão descobrir outros ambientes diferentes do de costume, e as atividades em sala vão ajudar na sua coordenação motora e conhecimentos de tipos diferentes de cada espécie trabalhada.

Ao invés de fazer uma síntese dos problemas em sala de aula ao se atender alunos com e sem necessidades especiais, este trabalho traz propostas de atividades práticas e lúdicas para o ensino de Botânica no $6^{\circ}$ ano do ensino fundamental, séries iniciais.

Estas atividades visam fazer com que o aluno se sinta parte da produção de conhecimento, ao fazer o mesmo procedimento que o pesquisador de botânica faz ao recolher um espécime na mata e o 
descrever. Depois disso, fazer atividades em sala com o material coletado por eles mesmos. Dessa forma o aluno se sente menos dependente do professor no processo de produção de conhecimento, sabendo que "pode fazer sozinho".

\section{A Botânica na Educação Inclusiva}

O presente trabalho tem por objetivo explorar a saída de campo como um auxílio didático, uma proposta pedagógica alternativa para ministrar conteúdo botânico no ensino fundamental, diante da realidade educacional. A escola, através dos professores, utiliza muitas vezes métodos e técnicas de ensino com uma concepção tradicional, provocando nos alunos indiferença pelos conteúdos ministrados.

Os alunos de $6^{\circ}$ ano vêm recém-chegados do $5^{\circ}$ ano, onde tinham "a professora" e o professor de Educação Física; eles estão em fase de adaptação com a realidade das diferenças pedagógicas, sociais e espaciais na nova realidade escolar. Agora são oito professores entrando e saindo de sala regularmente, precisam de disciplina para não se perder na ordem das matérias no caderno, e principalmente em suas cabecinhas. Nesse contexto um currículo engessado e aulas puramente teóricas têm pouco a contribuir para a formação desses educandos.

No caso do ensino de botânica no $6^{\circ}$ ano, encontra-se dificuldades, pois os alunos não são plenamente alfabetizados ao ponto de compreender os conteúdos apenas com a leitura. 
Ensinar a ler vai muito além de ensinar a decodificar palavras em um texto. Significa ensinar os alunos a usar estratégias de leitura na busca da construção e reconstrução dos significados das características das plantas e fazer sua identificação compreendendo os usos delas. Os alunos portadores de necessidades especiais, em sua maioria, apresentam dificuldades de leitura e, conseqüentemente, de escrita; para tal é necessário um tipo de abordagem diferente, através do reconhecimento das plantas com os conteúdos relativos a elas.

Por exemplo, as plantas latifoliadas:

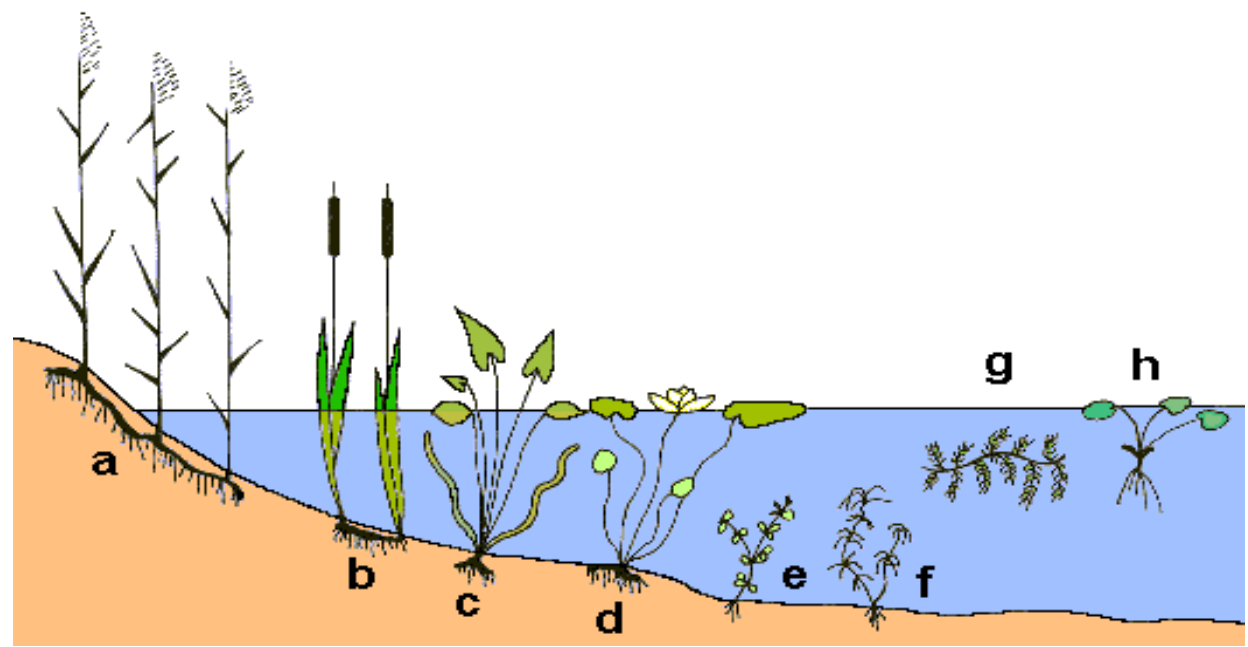

Figura 1 Planta Higrófita, são formações vegetais típicas de regiões úmidas, possuem folhas largas (latifoliadas) e perenes (perenifólias) para facilitar a transpiração excessiva em florestas tropicais.

Latifoliada: é uma palavra longa e complicada, praticamente um trava-língua, que a criança não reconhece imediatamente como uma planta familiar. Torna-se necessário explicar a origem gramatical da 
palavra e então apresentar a planta para a criança, seja em imagem, vídeo ou levando até o jardim da escola.

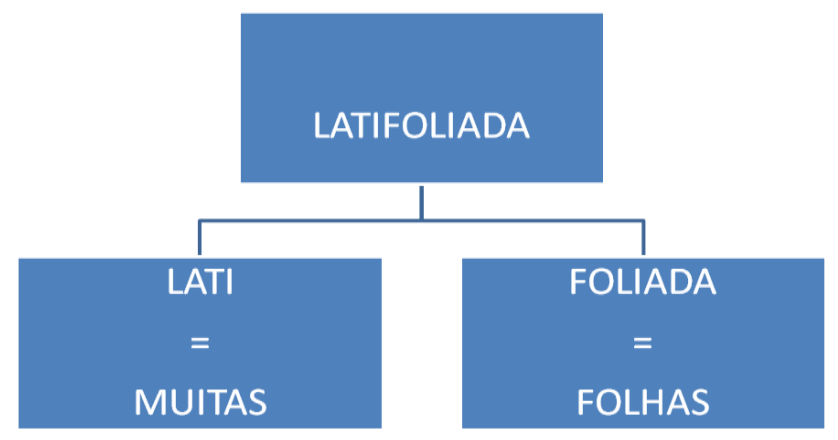

A educação inclusiva é uma ação educacional humanística, democrática, amorosa, mas não piedosa, que percebe o sujeito em sua singularidade e que tem como objetivos o crescimento, a satisfação pessoal e a inserção social de todos.

O conceito de educação inclusiva surgiu a partir de 1994, com a Declaração de Salamanca, a idéia é que as crianças com necessidades educacionais especiais sejam incluídas em escolas de ensino regular, algumas escolas dedicam-se apenas a um tipo de necessidade, enquanto que outras se dedicam a vários. $\mathrm{O}$ ensino especial é mais freqüente em instituições destinadas a acolher deficientes, isto tem sido alvo de críticas, por não promoverem o convívio entre as crianças especiais e as restantes crianças, no entanto, é necessário admitir que a 
escola regular nem sempre consiga oferecer uma resposta capaz de atender as diversas necessidades destas crianças. ${ }^{3}$

O sistema regular de ensino precisa adaptar-se, caso deseje promover a inclusão. Hoje já se conhecem mais escolas a adaptarem-se e a tornarem-se inclusivas. Para que o ensino especial nas escolas regulares seja de qualidade e consiga atender às diferenças individuais de cada criança, é necessária uma adaptação com o espaço e uma didática diferenciada na educação.

Os fundamentos legais dessa diferenciação estão dispostos nas Diretrizes Nacionais para a Educação Especial na Educação Básica, instituída pela RESOLUÇÃO CNE/CEB N 2, DE 11 DE SETEMBRO DE 2001

(...) assegura e serviços educacionais especiais, organizados institucionalmente para apoiar, complementar, suplementar e, em alguns casos, substituir os serviços educacionais comuns, de modo a garantir a educação escolar e promover o desenvolvimento das potencialidades dos educandos. ${ }^{4}$

No Art. 5’, que considera "educandos com necessidades educacionais especiais os que, durante o processo educacional,

3 COMUNIDADES.NET. Educação Inclusiva/ Especial. s/d. Disponível em : http://www.deficiencia.no.comunidades.net/index.php?pagina=1115276908. Acesso em: 24 maio 2014.

${ }^{4}$ BRASIL. Diretrizes Curriculares Nacionais da Educação Básica. Brasília: MEC, SEB, DICEI, 2013. 
apresentem (...) inciso III - altas habilidades/superdotação, grande facilidade de aprendizagem que o leva a dominar rapidamente conceitos, procedimentos e atitudes", e, ainda, no Art. $8^{\circ}$, que enfatiza que

As escolas da rede regular de ensino devem prever e prover na organização de suas classes comuns: (...) serviços de apoio pedagógico especializado em salas de recursos, nas quais o professor especializado em educação especial realize a complementação ou suplementação curricular, utilizando procedimentos, equipamentos e materiais específicos. ${ }^{5}$

A inclusão de alunos portadores de necessidades especiais é um direito destes ao convívio social e ao acesso ao conhecimento, e as escolas vêm buscando promover isto. Métodos e práticas pedagógicas estão sendo desenvolvidos para tornar essa inclusão plena e real.

O ensino de inclusão propõe que o professor sirva de modelo para seus alunos mediante a sua própria leitura: lê em voz alta, para sistematicamente verbalizar e comentar os processos que lhes permitem compreender o texto, por exemplo, as hipóteses que realizam os indicadores em que se baseia para verificá-las; também comenta as dúvidas que encontra, as falhas de compreensão e os mecanismos que utiliza para resolvê-las ${ }^{6}$.

\footnotetext{
${ }^{5}$ Idem. Ibidem.

${ }^{6}$ SOLÉ, Isabel. Estratégias de Leitura. 6. ed. Porto Alegre: Artmed, 1998.
} 
Depois a participação do aluno, de uma forma mais dirigida pelo professor, por exemplo, formulando apenas perguntas que sugiram hipóteses bastante determinadas sobre o conteúdo do texto, sugerindo perguntas abertas, ou apenas elucidando as opiniões dos alunos, o aluno participa do uso de estratégias que vão lhe facilitar a compreensão dos textos.

As primeiras propostas vistas foram no ensino de língua portuguesa, mas isso não é uma exclusividade. Com o desenvolvimento de botânica, entenda-se a leitura das plantas dentro de uma perspectiva multisensorial utilizando o tato, a visão e o olfato na identificação das plantas, com o propósito de:

- Alargar horizontes levando o mundo para dentro da sala de aula.

- Aprender fazendo.

- Melhorar capacidades intelectuais tais como a criatividade e a eficácia.

- Que um professor ensine simultaneamente em vários locais.

-Vários ritmos de aprendizagem na mesma turma.

- Motivar o aluno a aprender continuamente, pois utiliza um meio com que ele se identifique.

- Aliviar a carga administrativa do professor, deixando mais tempo livre para dedicar ao ensino e à ajuda a nível individual.

- Estabelecer a ponte entre a comunidade e a sala de aula $^{7}$.

${ }^{7}$ COMUNIDADES.NET. Op. cit. 
O uso da metodologia multisensorial traz benefícios tanto quantitativos, através do aumento do número de alunos participando efetivamente das aulas, quanto qualitativos, pelo aumento da quantidade de informações que recebem. Dentro da concepção desta metodologia, a visão, o tato e o olfato deixam de ser capacidades isoladas, promovendo a captação de um maior número de informações através de todos os sentidos que um indivíduo possa pôr em funcionamento ${ }^{8}$.

Assim, a prática do estudo de botânica com a leitura de textos e a leitura multisensorial promove o conhecimento das plantas e pode despertar em crianças especiais o interesse e a motivação pela descoberta dos vegetais:

[...] que acrescenta sentido novo ao universo de conhecimentos dos alunos, é aquela que estabelece continuamente a relação entre a teoria estudada e a realidade vivida. ${ }^{9}$

A deficiência deve ser encarada não como uma impossibilidade, mas como uma força, onde o uso de novas metodologias pode desempenhar um papel significante. ${ }^{10}$

8 ANJOS, Paola Trama Alves dos; CAMARGO, Eder Pires de. Didática Multissensorial: algumas considerações. $2^{\circ}$ Encontro sobre Divulgação e Ensino de Ciências. São Paulo, 2011. Disponível em: http://www.valdeci.bio.br/pdf/encartes/resumos_ec/EC28.pdf. Acesso em: 24 maio 2014.

${ }^{9}$ CARlini, A. L. E Agora: Preparar a Aula.... In: SCARPATO, M. (Org.). Os procedimentos de ensino fazem a aula acontecer. São Paulo: Avercamp, 2004. p. 127.

${ }^{10}$ COMUNIDADES.NET. Op. cit. 
Exemplo de leitura olfativa: Identificação da Salsinha e do Coentro.

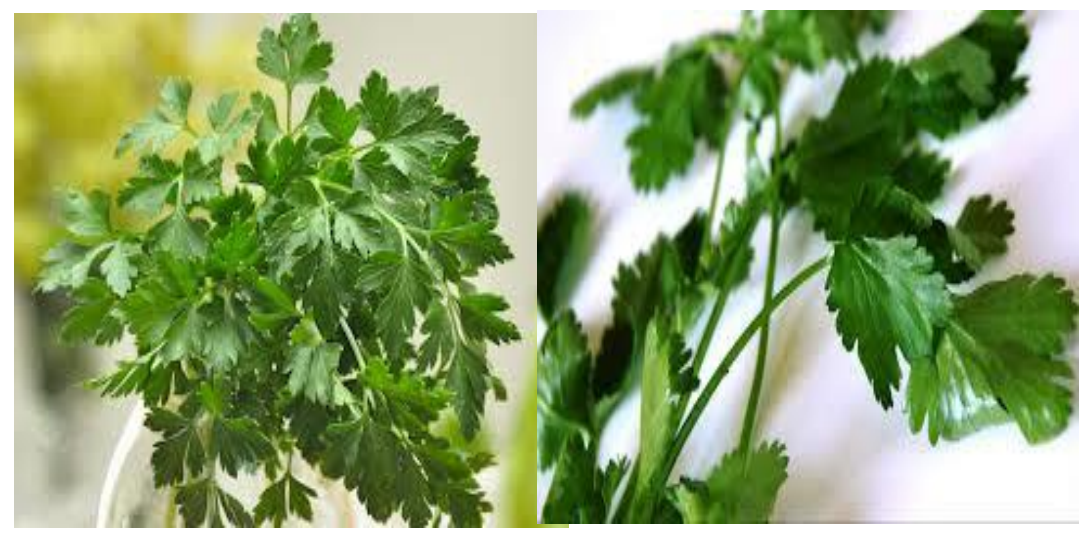

Figura 2. Folha de Salsinha ${ }^{11}$.

Figura 3. Folha de Coentro ${ }^{12}$

Trata-se de plantas idênticas; para saber a diferença é preciso amassar a folha e sentir o cheiro, para a sua identificação.

Exemplo de leitura tátil: As sensações provocadas pelo Capim Limão e pela folha da Violeta

${ }^{11}$ Disponível em : https://www.google.com.br/\#q=salsinha

${ }^{12}$ Disponível em: https://www.google.com.br/\#q=coentro 


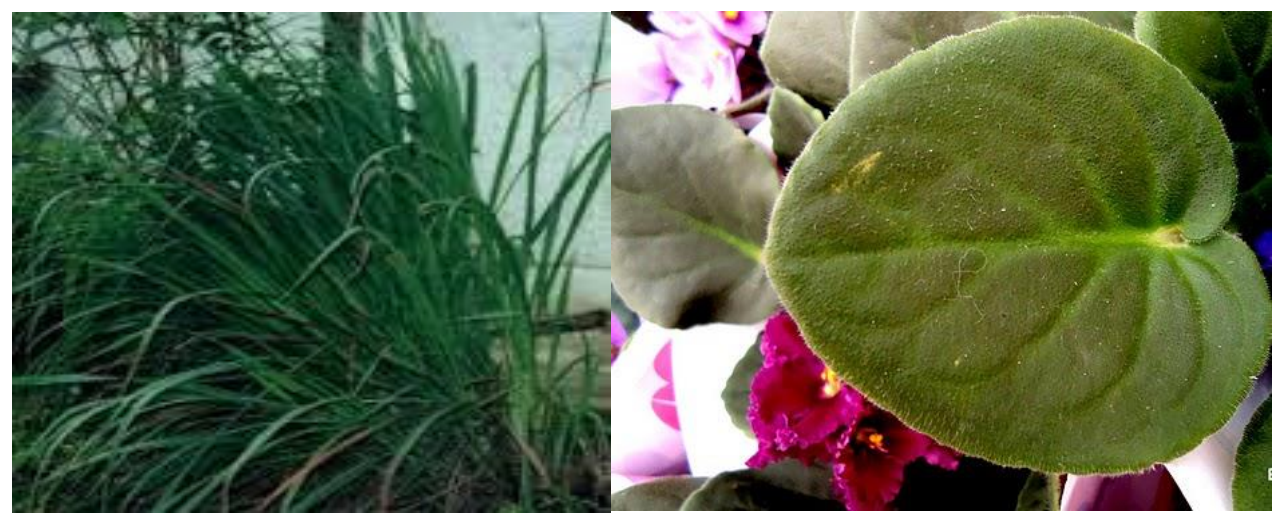

Figura 4. Planta de Capim Limão ${ }^{13}$. Figura 5.Folha de Violeta ${ }^{14}$.

Tocando nelas percebe-se que a folha de capim limão é áspera e pegajosa e a folha de violeta aveludada, com penugens e mais sensível.

Exemplo de leitura visual:

Comparação entre as folhas de Samambaia e Antúrio

${ }^{13}$ Disponível em: https://www.google.com.br/\#q=capim+lim\%C3\%A3o

${ }^{14}$ Disponível em: https://www.google.com.br/\#q=folha+de+orqu\%C3\%ADdea

Revista Vernáculo n. ${ }^{\circ} 40$ - segundo semestre /2017

ISSN 2317-4021 


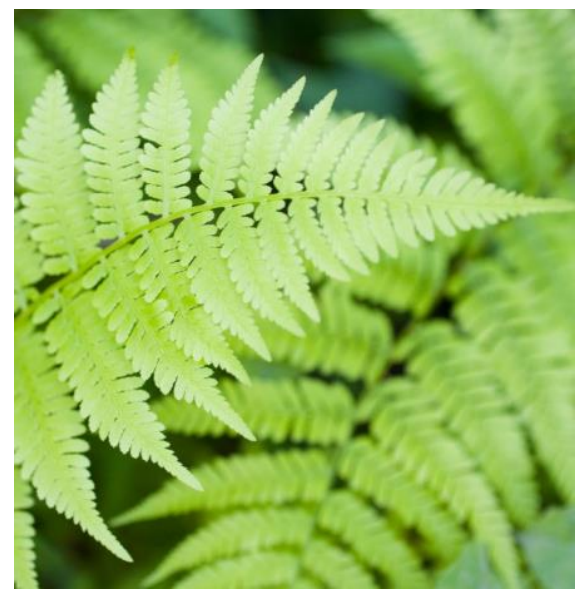

Figura 6. Folha de Samambaia ${ }^{15}$.

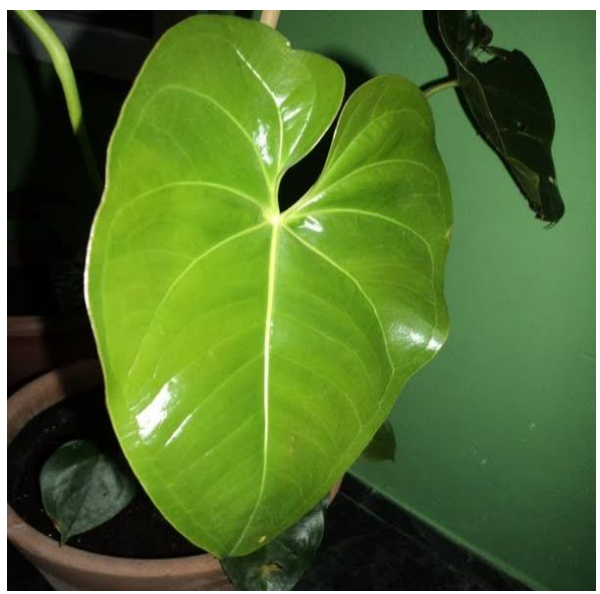

Figura 7. Folha de Antúrio ${ }^{16}$.

As samambaias são plantas pteridófitas com folhas finas e longas, e a folha do antúrio é grande com formato de coração (cordiforme), com fácil diferenciação na visualização.

As principais funções das aulas práticas, reconhecidas na literatura sobre o ensino de Ciências, são: despertar e manter o interesse dos alunos; envolver os estudantes em investigações científicas; desenvolver a capacidade de resolver problemas; compreender conceitos básicos e desenvolver habilidades ${ }^{17}$ (KRASILCHIK, 2005).

\footnotetext{
${ }^{15}$ Disponível em: https://www.google.com.br/\#q=folha+de+samambaia

${ }^{16}$ Disponível em: https://www.google.com.br/\#q=folha+de+anturio

17 Luan Cardoso de Menezes (1) Vênia Camelo de Souza (3) Mário Pereira Nicomedes (2) [???]
} 


\section{Propostas de atividade}

Fazer com que os alunos conheçam variedades de espécies de plantas, usando alguns dos sentidos, com saídas de campo, demonstrações em sala com figuras, vídeos e folhas vivas.

Atividade 1

Fazendo trabalho de folha em papel tamanho A4 com folhas vivas, pintando com o lápis, utilizando tinta guache para identificar o limbo, pecíolo e a bainha de cada folha para conhecer sua diferenciação entre as demais e simetria das folhas com lápis de cor.

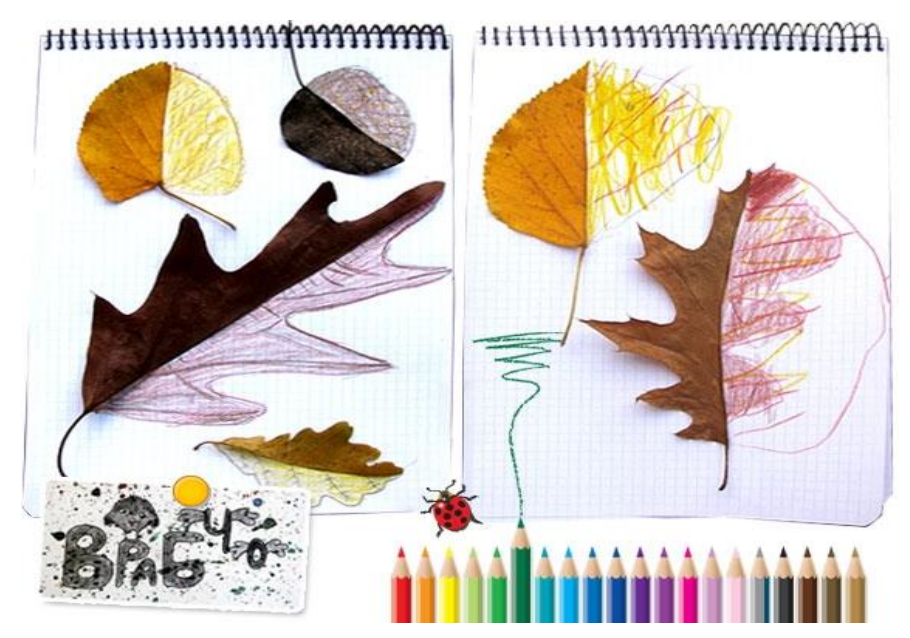

Figura 8. Reproduzindo a folha original ${ }^{18}$.

18 KRASILCHIK, M. Prática de Ensino de Biologia. São Paulo: Editora da Universidade de São Paulo, 2005. 
Atividade 2

Atividade com guache, fazendo os alunos passarem tintas coloridas na parte de trás da folha e depois carimbá-la no papel A4, deixando as suas "impressões digitais", e assim também analisar limbo, pecíolo e bainha.

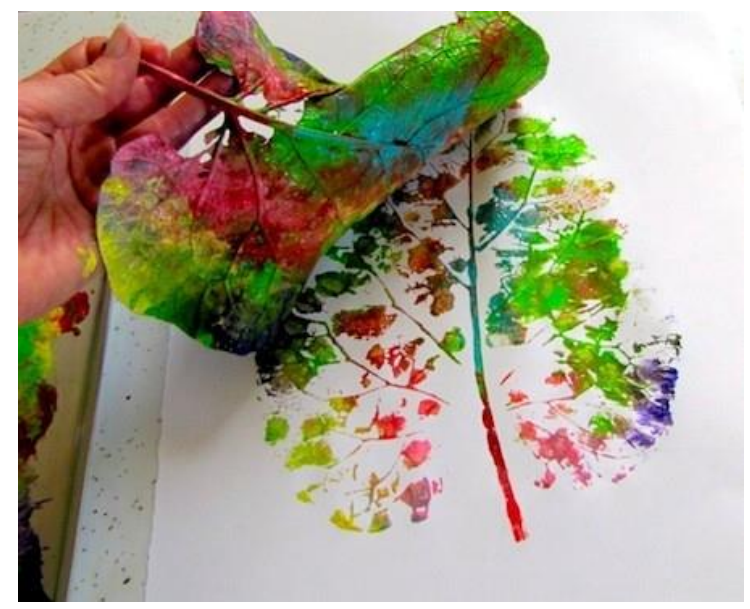

Figura 9. Impressão da folha com tinta guache ${ }^{19}$.

Atividade 3

Plantar feijão no algodão e acompanhar seu crescimento para identificar cada etapa do ciclo de vida da planta. 


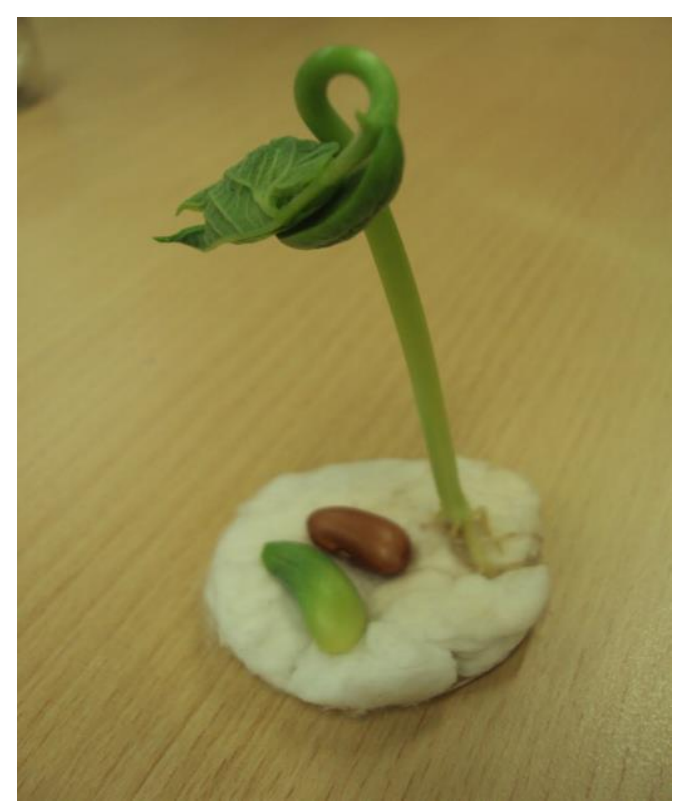

Figura 10. Broto de Feijão do algodão ${ }^{20}$.

Atividade 4

Plantar semente de girassol na terra e mostrar que ela cresce sempre voltada para a luz. 


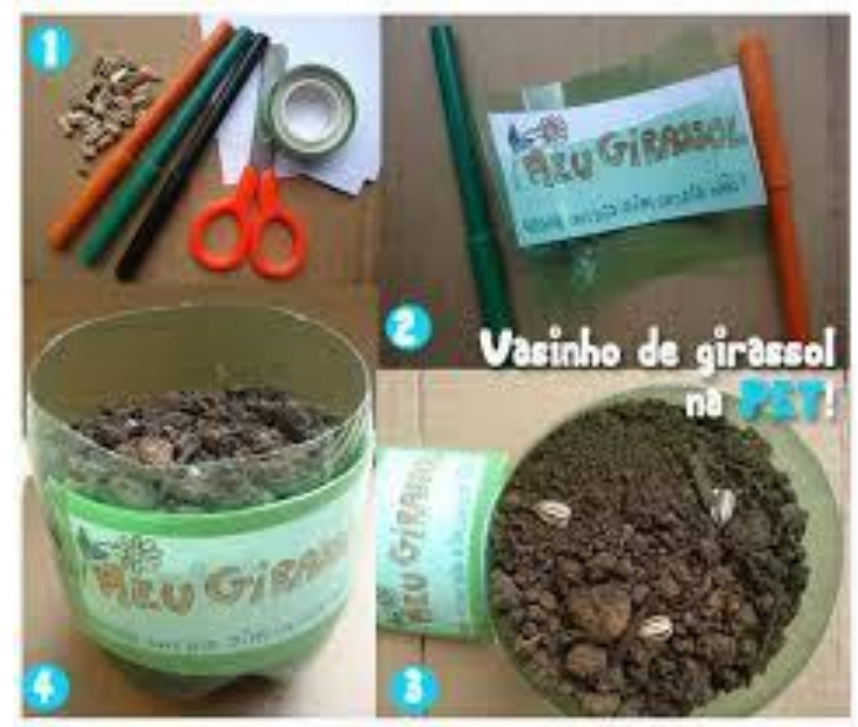

Figura 11. Plantando Girassol na Terra ${ }^{21}$.

Explicando que para o desenvolvimento de uma planta precisamos plantar a semente em um local onde ela receba luz, água, terra, ar, no caso da semente de feijão no algodão podemos observar a duração de dias para a germinação e acompanhar esse processo até ser preciso passar a planta para o solo, em um determinado momento ela não pode mais ficar no algodão, pois o seu processo de desenvolvimento fica prejudicado devido à falta de terra.

Estas atividades propostas podem auxiliar e muito no ensino de Botânica não apenas para os alunos portadores de necessidades

\section{${ }^{21}$ Disponível} em: https://www.google.com.br/search?q=plantando+girassol\&tbm=isch\&tbo=u\&source= univ\&sa $=$ X\&ei $=$ X 4 WCU93FOpOGqgbd54CQDg\&sqi $=2 \&$ ved $=0$ CCwQsAQ\&biw $=12$ $80 \&$ bih $=624 \#$ imgdii $=$ 
especiais. Estas atividades, voltadas para o uso de múltiplos sentidos, estimulam todos os alunos. O conhecimento apresentado de forma tradicional e experimentado de forma lúdica faz com que os alunos compreendam melhor o que o professor quis dizer, e se sintam estimulados a participar mais das aulas, já que elas "são divertidas".

Usar o lúdico em sala de aula não é enrolar com brincadeiras para passar o tempo, e sim dar uma outra abordagem, mais dinâmica, aos conteúdos que devem ser trabalhados. Esse lúdico, como o uso da tinta guache e os desenhos das folhas, é orientado e focado, objetivando uma produção específica de reconhecimento das plantas para serem posteriormente descritas conforme a taxonomia.

\section{Considerações Finais}

A educação inclusiva é um processo ainda em construção que visa a igualdade de oportunidades inclusive no acesso ao conhecimento. As dificuldades enfrentadas pelos alunos no processo de ensinoaprendizagem podem estar relacionadas a diversas situações: aulas tradicionais pautadas apenas nos textos didáticos, falta de preparo e paciência por parte do profissional da educação, preconceitos, etc.

Para que a criança se sinta envolvida e motivada ao desenvolver a atividade prática em Botânica, precisa pensar que sua atuação será eficaz, ou pelo menos que não será um desastre total. Só com ajuda e confiança esta atividade deixará de ser uma prática 
enfadonha para alguns e tornar-se o que sempre deveria ser: um desafio estimulante.

Trabalhando com as plantas faz-se com que os alunos com necessidades especiais tenham o conhecimento de diferentes espécies e se sintam motivados, pois mostra o interesse em querer ensinar e fazer da aula de campo ou das atividades em sala um momento agradável.

Dessa forma o aluno pode levar essa experiência para sua vida, como apertar saquinhos da flor de beijinho, ver estourar para cair as sementes ou fazer brincadeiras com as mamonas vendo que por causa dos espinhos elas grudam na roupa. Coisas corriqueiras que fizemos na infância, sem nos dar conta de estarmos sendo agentes no ciclo de vida dessas plantas ao distribuirmos suas sementes em nossas brincadeiras. Quem nunca soprou um dente de leão?

Foram elencadas diferentes propostas de atividades que podem ser realizadas com os alunos do $6^{\circ}$ ano do ensino fundamental e os possíveis resultados destas atividades, de acordo com os relatos dos professores que já realizaram tais atividades.

Os alunos demonstraram maior facilidade em assimilar as formas e nomes das partes das plantas ao relacioná-las com suas texturas e cores. $\mathrm{O}$ interesse pela disciplina também aumentou, já que ficavam na expectativa de uma nova atividade prática; sair da rotina os estimulava a querer participar das aulas.

Os alunos portadores de alguma necessidade especial, do ponto de vista do professor, alcançaram igual nível de rendimento dos demais, 
principalmente por perceberem que tinham as mesmas dificuldades que os outros em identificar as plantas, precisando tocá-las, cheirá-las, desenhá-las com seus próprios recursos motores e visuais, para então assimilar cada uma e fazer a sua classificação. Através dessas atividades foi possível trabalhar a diversidade a partir de problemas comuns a todos os alunos, e que minimizavam o fato de alguns alunos serem portadores de necessidades especiais. Pois na hora de conhecer o novo e aprender a trabalhar com ele, "todos" precisam de atenção especial.

\section{Referências}

ANJOS, Paola Trama Alves dos; CAMARGO, Eder Pires de. Didática Multissensorial: algumas considerações. $\mathbf{2}^{\circ}$ Encontro sobre Divulgação e Ensino de Ciências. São Paulo, 2011. Disponível em: http://www.valdeci.bio.br/pdf/encartes/resumos_ec/EC28.pdf. Acesso em: 24 maio 2014.

BRASIL. Diretrizes Curriculares Nacionais da Educação Básica. Brasília: MEC, SEB, DICEI, 2013.

CARLINI, A. L. E Agora: Preparar a Aula.... In: SCARPATO, M. (Org.). Os procedimentos de ensino fazem a aula acontecer. São Paulo: Avercamp, 2004.

COMUNIDADES.NET. Educação Inclusiva/ Especial. s/d.

Disponível em: 
http://www.deficiencia.no.comunidades.net/index.php?pagina=1115276 908. Acesso em: 24 maio 2014.

KRASILCHIK, M. Prática de Ensino de Biologia. São Paulo: Editora da Universidade de São Paulo, 2005, 197p.

SILVA, Natalí Azevedo da; QUIRINO, Max Rocha; OLIVEIRA, Ademir Guilherme de; RONELLI, Rodrigo; ANDRADE, Duarte de; SANTOS, Betânia Araújo Cosme dos. Iniciativas para o aprendizado de Botânica no Ensino Médio.. XI Encontro de Iniciação à Docência. UEPG.

Disponível

em: http://atividadeseducativas.org/category/outono/. Acesso em: 25 maio 2014.

SOLÉ, Isabel. Estratégias de Leitura. 6. ed. Porto Alegre: Artmed, 1998.

Recebido em 23/07/2015, aceito para publicação em 20/06/2017 